\title{
Growth of Bacillus subtilis on citrate and isocitrate is supported by the $\mathrm{Mg}^{2+}$-citrate transporter CitM
}

\author{
Jessica B. Warner and Juke S. Lolkema
}

Molecular Microbiology, Groningen Biomolecular Sciences and Biotechnology Institute, University of Groningen, Kerklaan 30, 9751 NN Haren, The Netherlands
Author for correspondence: Juke S. Lolkema. Tel: +31 50 3632155. Fax: +31503632154. e-mail: j.s.lolkema@biol.rug.nl

Bacillus subtilis 168 was assayed for its growth on tricarboxylic acid (TCA) cycle intermediates and related compounds as the sole carbon sources. Growth of the organism was supported by citrate, D-isocitrate, succinate, fumarate and L-malate, whereas no growth was observed in the presence of cis-aconitate, 2-oxoglutarate, D-malate, oxaloacetate and tricarballylate. Growth of the organism on the tricarboxylates citrate and D-isocitrate required the presence of functional CitM, an $\mathrm{Mg}^{2+}$-citrate transporter, whereas its growth on succinate, fumarate and L-malate appeared to be CitM-independent. Interestingly, the naturally occurring enantiomer $D$-isocitrate was favoured over L-isocitrate by the organism. Like citrate, D-isocitrate was shown to be an inducer of citM expression in B. subtilis. The addition of $1 \mathrm{mM} \mathrm{Mg^{2+ }}$ to the growth medium improved growth of the organism on both citrate and D-isocitrate, suggesting that $D$-isocitrate was taken up by CitM in complex with divalent metal ions. Subsequently, the ability of CitM to transport D-isocitrate was demonstrated by competition experiments and by heterologous exchange in right-side-out membrane vesicles prepared from $E$. coli cells expressing citM. None of the other TCA cycle intermediates and related compounds tested were recognized by CitM. Uptake experiments using radioactive ${ }^{63} \mathrm{Ni}^{2+}$ provided direct evidence that $\mathrm{D}$-isocitrate is transported in complex with divalent metal ions.

Keywords: TCA cycle intermediate, promoter fusion, divalent metal ion-citrate complex, membrane vesicles, exchange

\section{INTRODUCTION}

The two main roles of the tricarboxylic acid (TCA) cycle in cell metabolism are to generate metabolic energy by producing reducing equivalents and to provide the cell with intermediates for anabolism. Bacillus subtilis runs a complete TCA cycle and is able to utilize almost all of the TCA cycle intermediates under aerobic conditions (Fortnagel \& Freese, 1968; Wei et al., 2000; Asai et al., 2000). Little is known about the identity and regulation of the transport systems responsible for the uptake of the growth substrates under these conditions. The uptake of the $\mathrm{C}_{4}$ dicarboxylates succinate and fumarate by $B$. subtilis during its growth on these substrates was shown to be mediated by the dicarboxylate transporter

Abbreviations: FCCP, carbonylcyanide $p$-trifluormethoxy-phenylhydrazone; MSMYE, minimal salts medium $/ 0.05 \%$ yeast extract; RSO, right-sideout; TCA, tricarboxylic acid.
DctP (Asai et al., 2000; Janausch et al., 2002). Expression of $d c t P$ is positively regulated in response to external signals by a sensor kinase and regulator pair, DctS and DctR. The regulatory system is induced in the presence of succinate, fumarate and low concentrations of yeast extract and is repressed by malate (Asai et al., 2000). Although it was not excluded that malate is also a substrate for the DctP transporter, several other transport systems have been shown to transport this compound. CimH $(y x k J)$ mediates the uptake of malate (and citrate) in symport with protons (Krom et al., 2001), MeaN (yufR) transports malate in symport with $\mathrm{Na}^{+}$ ions (Wei et al., 2000) and MleN (yqkI) was shown to be a malate/lactate exchanger that couples the exchange reaction to proton uptake and $\mathrm{Na}^{+}$efflux (Wei et al., 2000). The role of the individual transporters during growth of $B$. subtilis on malate is unknown.

Older studies have reported the ability of the TCA cycle intermediates cis-aconitate and isocitrate to induce and 
competitively inhibit the uptake of citrate in wild-type cells of B. subtilis, suggesting the presence of a specific transport system in this organism (McKillen et al., 1972). More-recent studies have identified a number of transporters for citrate in B. subtilis. $\mathrm{CimH}$, mentioned above, catalyses symport of citrate and protons (Krom et al., 2001). The secondary transporters CitM and CitH also transport citrate in symport with protons, but only in the presence of divalent metal ions (Boorsma et al., 1996; Krom et al., 2000). Uptake studies of the two transporters separately expressed in E. coli cells confirmed that the metal ion-citrate complex is the transported species and that the metal-ion specificity of the two transporters is complementary, i.e. CitM transports citrate in complex with $\mathrm{Mg}^{2+}, \mathrm{Mn}^{2+}, \mathrm{Ni}^{2+}, \mathrm{Co}^{2+}$ or $\mathrm{Zn}^{2+}$, and $\mathrm{CitH}$ recognizes citrate in complex with $\mathrm{Ca}^{2+}$, $\mathrm{Ba}^{2+}$ or $\mathrm{Sr}^{2+}$ (Krom et al., 2000). Expression of citM is strictly regulated: gene activation depends on the action of the two-component regulatory pair CitS-CitT, which senses the presence of citrate in the medium (Yamamoto et al., 2000). Furthermore, gene expression is subject to catabolite repression (Warner et al., 2000). The strict regulation of cit $M$ expression by medium components makes it likely that CitM is the main uptake system during growth of $B$. subtilis on citrate as the sole carbon source.

Here, we have studied the involvement of the $\mathrm{Mg}^{2+}-$ citrate transporter CitM in the growth of B. subtilis on TCA cycle intermediates. It follows that CitM is both necessary and sufficient for growth of the organism on citrate as the sole carbon source. In addition, it is shown that CitM supports the growth of B. subtilis on isocitrate which, like citrate, is shown to be an inducer of citM expression. Subsequently, transport studies using membrane vesicles and resting cells demonstrated that CitM transports the complex of isocitrate and divalent metal ions.

\section{METHODS}

Bacterial strains and growth conditions. The bacterial strains used in this study were B. subtilis 168 (trpC2), CITMd (trpC2 $\Delta c i t M$ ery) (Yamamoto et al., 2000) and CM002 [trpC2 amyE::( $\mathrm{P}_{\text {cit } M}$-lacZ cat)] (Warner et al., 2000), and E. coli TOP10 ( $\phi 80 \Delta l a c Z M 15 \Delta l a c X 74$ recA; Invitrogen). Precultures of $B$. subtilis were grown overnight at $37^{\circ} \mathrm{C}$ in Luria-Bertani (LB) or CSE medium, to which tryptophan was added to a final concentration of $20 \mu \mathrm{g} \mathrm{ml}^{-1}$. CSE medium was C medium (Aymerich et al., 1986) to which sodium succinate $\left(6 \mathrm{~g} \mathrm{l}^{-1}\right)$ and potassium glutamate $\left(8 \mathrm{~g} \mathrm{l}^{-1}\right)$ was added. LBgrown pre-cultures were diluted 200 times in minimal salts medium $\left(2 \cdot 72 \mathrm{~g} \mathrm{~K}_{2} \mathrm{HPO}_{4}, 1 \mathrm{~g} \mathrm{KH}_{2} \mathrm{PO}_{4}, 1 \mathrm{~g} \mathrm{NH}{ }_{4} \mathrm{Cl}, 0.284 \mathrm{~g}\right.$ $\mathrm{Na}_{2} \mathrm{SO}_{4}, 0.17 \mathrm{~g} \mathrm{NaNO}_{3}, 0.15 \mathrm{~g} \mathrm{KCl}, 25 \mathrm{mg} \mathrm{MgCl} .6 \mathrm{H}_{2} \mathrm{O}$, $22 \mathrm{mg} \mathrm{CaCl}_{2} \cdot 6 \mathrm{H}_{2} \mathrm{O}, 15 \mathrm{mg} \mathrm{MnCl}_{2} \cdot 4 \mathrm{H}_{2} \mathrm{O}$ and $2 \cdot 16 \mathrm{mg}$ $\mathrm{FeCl}_{3} \cdot 6 \mathrm{H}_{2} \mathrm{O}$ per litre of medium) containing $0.05 \%$ yeast extract (MSMYE medium) (Goel et al., 1995; Asai et al., 2000). TCA cycle intermediates were added to the medium at a final concentration of $5 \mathrm{mM}$ after growth of the cells for $2 \cdot 5 \mathrm{~h}\left(\mathrm{OD}_{660} \sim 0 \cdot 1\right)$. CSE-grown pre-cultures were diluted 25 times in CSE supplemented with $5 \mathrm{mM}$ trisodium citrate, DLisocitrate or cis-aconitate. The cells were grown in flasks under continuous shaking at 150 r.p.m. Growth was moni- tored by measuring the optical density at $660 \mathrm{~nm}$. When appropriate, antibiotics were added to the medium at the following concentrations : $5 \mu \mathrm{g}$ chloramphenicol ml ${ }^{-1} ; 0.3 \mu \mathrm{g}$ erythromycin $\mathrm{ml}^{-1} ; 50 \mu \mathrm{g}$ ampicillin $\mathrm{ml}^{-1}$. Qualitatively, $\beta$ galactosidase activity was measured by growing the cells on agar plates containing LB medium and $10 \mathrm{mM}$ of the different carbon sources and $5 \%$ of the chromogenic substrate X-Gal.

E. coli TOP10 was transformed with plasmid pWSKCitM, which contains the gene encoding the $\mathrm{Mg}^{2+}$-citrate transporter CitM under the control of the lac promoter (Krom et al., 2000). Recombinant cells were grown in LB medium supplemented with $100 \mu \mathrm{g}$ carbenicillin $\mathrm{ml}^{-1}$ and were induced with $0 \cdot 1 \mathrm{mM}$ IPTG at an $\mathrm{OD}_{660}$ value of $0 \cdot 2$, after which the cells were allowed to grow for an additional $2 \mathrm{~h}$.

Preparation of membrane vesicles. E. coli TOP10 cells expressing CitM were harvested at an $\mathrm{OD}_{660}$ value of $0 \cdot 8-1 \cdot 0$ and right-side-out (RSO) membrane vesicles were prepared by the osmotic shock lysis procedure described by Kaback (1983). The vesicles were resuspended in $50 \mathrm{mM}$ potassium PIPES ( $\mathrm{pH} 6.5$ ), aliquoted in $0.5 \mathrm{ml}$ samples, rapidly frozen in liquid nitrogen and, subsequently, stored at $-80{ }^{\circ} \mathrm{C}$. The protein concentration was determined with the Bio-Rad DC Protein Assay Kit.

\section{Transport assays.}

(i) ${ }^{63} \mathrm{Ni}^{2+}$ uptake in whole cells. Cells of $B$. subtilis were harvested by centrifugation, washed once and resuspended in $50 \mathrm{mM}$ potassium PIPES ( $\mathrm{pH}$ 6.5) and stored on ice until use. Transport activity was determined by the rapid-filtration method (Lolkema et al., 1994). Briefly, $98 \mu \mathrm{l}$ of a cell suspension with a final $\mathrm{OD}_{660}$ value of 1 was incubated for 5 min at $30{ }^{\circ} \mathrm{C}$. At time-point zero, $2 \mu \mathrm{l}$ of a mixture of ${ }^{63} \mathrm{Ni}^{2+}$ [12.66 $\mathrm{mCi}(\mathrm{mg} \mathrm{Ni})^{-1}, 468 \mathrm{MBq}\left(\mathrm{mg} \mathrm{Ni}^{-1}\right.$; Amersham] and citrate or DL-isocitrate was added to the cell suspension, yielding a final concentration of $12.5 \mu \mathrm{M}^{63} \mathrm{Ni}^{2+}$ and $0 \cdot 125-$ 2.5 mM citrate or 1-10 mM DL-isocitrate. Samples were taken at time points between 0 and $5 \mathrm{~min}$. Uptake of ${ }^{63} \mathrm{Ni}^{2+}$ was stopped by the addition of $2 \mathrm{ml}$ of ice-cold $0 \cdot 1 \mathrm{M} \mathrm{LiCl}$ to the suspension, immediately followed by filtration of the suspension through a $0.45 \mu \mathrm{m}$ pore-size nitrocellulose filter. The filters were washed once with the same $\mathrm{LiCl}$ solution and submerged in scintillation fluid. The retained radioactivity was counted in a liquid scintillation counter. Uptake rates were determined from the linear part of each uptake curve.

(ii) $\left[1,5-{ }^{14} \mathrm{C}\right]$ citrate uptake in membrane vesicles of $E$. coli. RSO membrane vesicles of E. coli TOP10 containing CitM were diluted in $50 \mathrm{mM}$ potassium PIPES ( $\mathrm{pH} \mathrm{6.5)} \mathrm{supplemented}$ with $10 \mathrm{mM} \mathrm{MgCl}_{2}$ to a final membrane protein concentration of 50 or $100 \mu \mathrm{g} \mathrm{ml}^{-1}$ in a total assay volume of $100 \mu \mathrm{l}$. An electrochemical proton gradient was allowed to develop at $30{ }^{\circ} \mathrm{C}$ for $2 \mathrm{~min}$ after the addition of $10 \mathrm{mM}$ potassium ascorbate and $100 \mu \mathrm{M}$ phenazine methosulfate to the assay mix under a flow of water-saturated air with magnetic stirring, after which the uptake was initiated by the addition of [1,5${ }^{14} \mathrm{C}$ ]citrate $\left(114 \mathrm{mCi} \mathrm{mmol}^{-1}, 4 \cdot 218 \mathrm{GBq} \mathrm{mmol}^{-1}\right.$; Amersham) to the assay mix to a final concentration of $4 \cdot 5 \mu \mathrm{M}$. The uptake of $\left[1,5-{ }^{14} \mathrm{C}\right]$ citrate was quenched and the samples were treated as described above. Inhibitors were present at a concentration of $1 \mathrm{mM}$.

(iii) Exchange in membrane vesicles of E. coli. RSO membrane vesicles were allowed to accumulate $\left[1,5-{ }^{14} \mathrm{C}\right]$ citrate or $\mathrm{L}$-[U${ }^{14} \mathrm{C}$ ]proline $\left(260 \mathrm{mCi} \mathrm{mmol}^{-1}, 9.62 \mathrm{GBq} \mathrm{mmol}^{-1}\right.$; Amersham) as described above for $1.5 \mathrm{~min}$. Subsequently, in exchange experiments, various substrates were added to the assay mixes 
at the indicated concentrations and the internalized label was followed over time. In efflux experiments, $10 \mu \mathrm{M}$ of the protonophore carbonylcyanide $p$-trifluormethoxy-phenylhydrazone (FCCP) was added to the assay mixes, which completely dissipates the proton motive force. Samples were taken between $10 \mathrm{~s}$ and $3 \mathrm{~min}$ and treated as described earlier.

$\beta$-Galactosidase assay. $\beta$-Galactosidase activity of the $B$. subtilis cells was determined at $28^{\circ} \mathrm{C}$ by the method of Miller (1972) using ONPG as the substrate. Cells from $2 \mathrm{ml}$ of a cell culture were harvested by centrifugation. The cell pellet was suspended in a buffer containing $100 \mathrm{mM}$ Na-phosphate, $10 \mathrm{mM} \mathrm{KCl} 1 \mathrm{mM} \mathrm{MgSO}_{4}$ and $1 \mathrm{mM}$ DTT (pH 7.0) and the cells were lysed using the lysozyme treatment in the presence of $10 \mu \mathrm{M}$ DNase. Specific $\beta$-galactosidase activities are expressed as the $O$-nitrophenol released per min per cell density at $28{ }^{\circ} \mathrm{C}$ (Miller units). The values reported are means of two independent measurements. Background activities were measured in B. subtilis 168 and amounted to $0 \cdot 3-0 \cdot 5$ Miller units.

\section{RESULTS}

\section{Involvement of CitM in growth of B. subtilis on TCA cycle intermediates}

The involvement of the $\mathrm{Mg}^{2+}$-citrate transporter CitM in growth of B. subtilis on TCA cycle intermediates and some related compounds was investigated using an assay developed by Asai et al. (2000). Growth of the cells was triggered in MSMYE medium. In the absence of an additional carbon source, growth of $B$. subtilis ceased at an $\mathrm{OD}_{660}$ value of $\sim 0.3$ (Fig. 1a), whereas upon the addition of, for instance, citrate (arrow Fig. 1b) the cells were able to keep on growing for several hours, indicating that they took up citrate and used it for growth. Similarly, DL-isocitrate, L-malate, succinate and fumarate supported growth of B. subtilis, whereas the addition of cis-aconitate, 2-oxoglutarate and oxaloacetate to the culture medium did not result in significant growth of the organism (Fig. 1c, e, f). The naturally occurring enantiomer D-isocitrate supported growth of B. subtilis better than the mixture of $\mathrm{D}$ - and L-isocitrate added to the culture medium at the same total concentration, indicating that the former is the preferred substrate of B. subtilis (compare Fig. 1c, d). Tricarballylate, which is structurally related to citrate and isocitrate but lacks the hydroxyl group, did not support growth of B. subtilis (Fig. 1g). Also, D-malate, in contrast to L-malate, did not support growth of the organism.

To determine the involvement of CitM in the uptake of any of the substrates that supported growth of B. subtilis, the experiment was repeated with the CitMdeficient strain CITMd (kindly provided by Professor Sekiguchi, Shinshu University, Japan). Growth of the mutant strain in MSMYE medium was similar to that observed for the wild-type strain B. subtilis 168 (Fig. 1a). In contrast to the wild-type strain, the CITMd mutant did not reveal enhanced growth when citrate was added to the medium (Fig. 1b), suggesting that CitM is the only transporter in the wild-type cells that is used for citrate uptake under the growth conditions used here. Similarly, no growth of the mutant was observed upon the addition of DL-isocitrate and D-isocitrate to the medium (Fig. 1c, d), whereas L-malate, succinate and fumarate supported growth of the wild-type and CITMd strains equally well (Fig. 1f, and not shown).

CitM is known to transport exclusively citrate complexed to divalent metal ions (Krom et al., 2000). The MSMYE medium contained $0.123 \mathrm{mM} \mathrm{Mg}^{2+}$, apparently enough to support growth on citrate, but citrate was present in the medium in large excess in this study $(5 \mathrm{mM})$. Accordingly, growth of $B$. subtilis on citrate was considerably improved when an additional concentration of $1 \mathrm{mM} \mathrm{MgCl} 2$ was added to the medium (Fig. 1b). Higher concentrations of citrate, up to $10 \mathrm{mM}$, did not further improve growth of the organism (not shown). Similarly, growth of B. subtilis on isocitrate was significantly improved in the presence of $1 \mathrm{mM} \mathrm{MgCl}{ }_{2}$, especially in the case of D-isocitrate (Fig. 1c, d). At higher $\mathrm{Mg}^{2+}$ concentrations, some enhancement of growth of the organism was observed on cis-aconitate (Fig. 1e; see Discussion). Apparently, growth of $B$. subtilis on these substrates had been limited by a low metal ion concentration in the medium. To exclude the possibility that the improved growth of $B$. subtilis in response to $\mathrm{Mg}^{2+}$ was due to the addition of $\mathrm{MgCl}_{2}$ itself, growth of the organism was followed in the presence of the poor growth substrate tricarballylate and the good growth substrate L-malate, which is utilized independently of CitM. In both cases, the addition of $1 \mathrm{mM} \mathrm{MgCl}{ }_{2}$ to the medium did not affect the growth characteristics of $B$. subtilis (Fig. 1h).

In summary, CitM supports growth of B. subtilis on citrate and $\mathrm{D}$-isocitrate in the presence of $\mathrm{Mg}^{2+}$. No apparent involvement of CitM was observed during growth of the organism on succinate, fumarate and L-malate, while no growth of the organism was observed in the presence of cis-aconitate, 2-oxoglutarate, D-malate, oxaloacetate or tricarballylate.

\section{Analysis of citM expression}

Expression of citM by $B$. subtilis was determined qualitatively by growing $B$. subtilis CM002, a strain that contains the lac $Z$ reporter gene fused behind the citM promoter region integrated into the chromosome (see Methods), on LB agar plates containing the chromogenic substrate X-Gal to monitor LacZ activity. Control plates scored negative. Supplementing the plates with different TCA cycle substrates revealed that besides citrate, DLisocitrate, $\mathrm{D}$-isocitrate and cis-aconitate were apparently able to induce citM expression in B. subtilis CM002 (not shown).

Induction of cit $M$ expression was followed over time during growth of $B$. subtilis CM002 on CSE minimal medium in the presence of citrate, DL-isocitrate and cisaconitate. The citM promoter activity was measured quantitatively by measuring the $\beta$-galactosidase activity of the cells during their growth. The cultures were inoculated with uninduced cells. In the presence of citrate, $\beta$-galactosidase activity of the cultures increased 

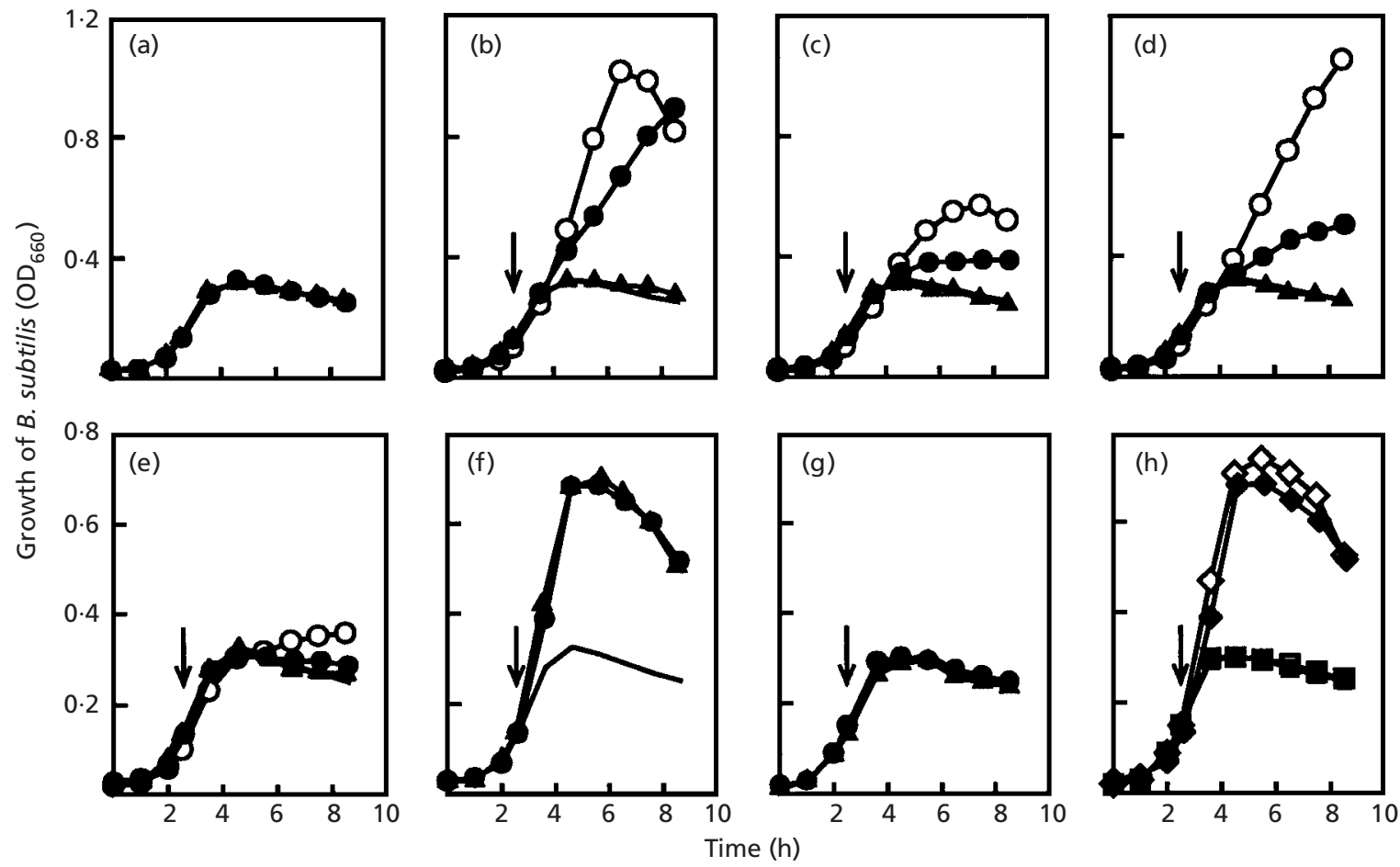

Fig. 1. Growth of $B$. subtilis on TCA cycle intermediates. $(a-g) B$. subtilis wild-type $(\boldsymbol{O}, O)$ and CITMd $(\boldsymbol{\Delta})$ were grown in MSMYE without further addition (a) or in the presence of $5 \mathrm{mM}$ of the carbon sources (b) citrate, (c) DL-isocitrate, (d) Disocitrate, (e) cis-aconitate, (f) L-malate or (g) tricarballylate. The open symbols ( $\bigcirc$ ) represent growth of the wild-type strain in medium to which an additional concentration of $1 \mathrm{mM} \mathrm{Mg}{ }^{2+}$ was added. The solid line representing growth of the wild-type strain in the absence of any carbon source $(a, 0)$ was copied to the other panels for easy reference. (h) Growth of the wild-type strain on L-malate $(\diamond, \diamond)$ and tricarballylate $(\boldsymbol{\square}, \square)$ in the absence $(\diamond, \boldsymbol{\square})$ or presence $(\diamond, \square)$ of $1 \mathrm{mM} \mathrm{Mg}{ }^{2+}$. The arrows indicate the time point of adding the carbon source.
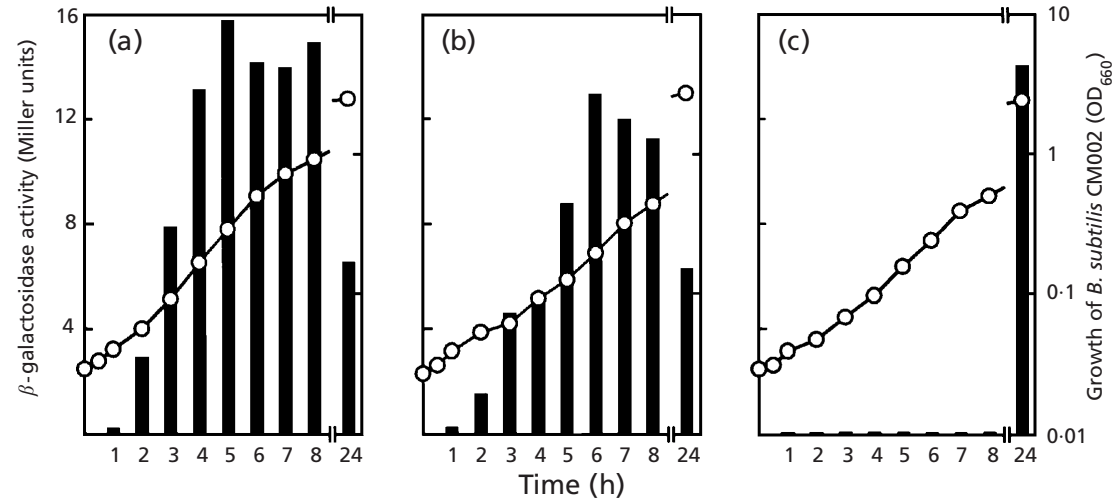

Fig. 2. Induction of citM expression. B. subtilis CM002 was grown in CSE minimal medium in the presence of $5 \mathrm{mM}$ (a) citrate, (b) DL-isocitrate or (c) cis-aconitate. Growth was followed by measuring the $\mathrm{OD}_{660}(O)$. The $\beta$-galactosidase activity correlating with the citM promoter activity was indicated in Miller units (solid bars).

to reach a steady-state value in the late-exponential phase of growth (Fig. 2a). The pre-steady-state period represents the time required for the $\beta$-galactosidase expression level to equilibrate between the synthesis rate and the growth rate (Warner \& Lolkema, 2002). A similar time dependence for $\beta$-galactosidase activity was observed when B. subtilis CM002 was grown in the presence of DL-isocitrate, but the level of expression appeared to be somewhat lower than that observed for citrate (Fig. 2b). No induction of expression by cisaconitate was observed during the exponential growth phase but, surprisingly, after $24 \mathrm{~h}$, long after the cells had entered the stationary phase, induction was as high as that observed during growth of the organism on citrate or DL-isocitrate (Fig. 2c). The differences in $\beta$ galactosidase activity levels in the exponential growth phase between B. subtilis CM002 cultures grown on citrate or DL-isocitrate and on cis-aconitate could not be explained by different growth rates (Warner \& Lolkema, 2002), since these were not affected much by the different substrates. To exclude the possibility that the observed induction of $\beta$-galactosidase activity by cis-aconitate 

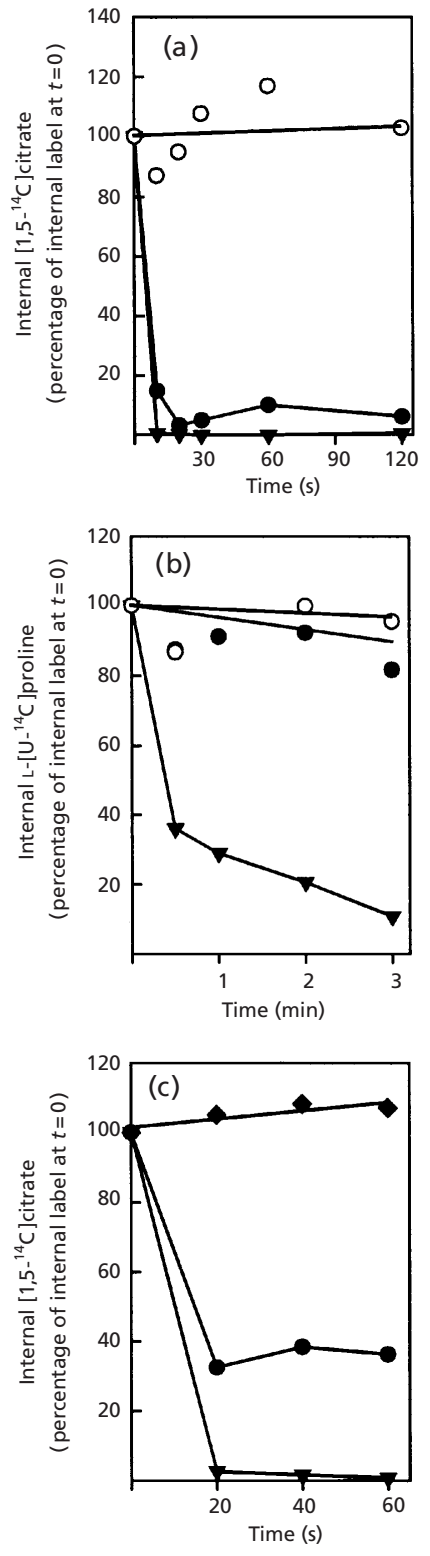

Fig. 3. Homologous and heterologous exchange catalysed by CitM. RSO membrane vesicles of $E$. coli expressing CitM were pre-loaded with $(a, c)\left[1,5-{ }^{14} \mathrm{C}\right]$ citrate or (b) L-[U- $\left.{ }^{14} \mathrm{C}\right]$ proline as described in Methods. ( $a, b)$ After pre-loading, at $t=0$, either no further additions were made $(O)$, or $1 \mathrm{mM}$ citrate $(\mathrm{a}, \mathrm{b}, \mathbf{0})$, $10 \mu \mathrm{M}$ FCCP $(a, b, \nabla), 1 \mathrm{mM}$ tricarballylate $(c, \diamond), 1 \mathrm{mM}$ cisaconitate $(c,-)$ or $1 \mathrm{mM}$ D-isocitrate $(c, \boldsymbol{\nabla})$ was added to the assay. The label retained by the membranes was indicated as the percentage of the internal label at $t=0$. The $100 \%$ value corresponded to (a) $0.62 \mathrm{nmol}$ (mg protein) $)^{-1}$, (b) $0.59 \mathrm{nmol}$ (mg protein $)^{-1}$ and (c) $1.16 \mathrm{nmol}(\mathrm{mg} \text { protein })^{-1}$.

might be the result of the slow conversion (hydration) of this TCA cycle intermediate into citrate or isocitrate during the course of bacterial growth, CSE minimal medium containing cis-aconitate was pre-incubated for $24 \mathrm{~h}$ at $37^{\circ} \mathrm{C}$ under continuous shaking before inoculation. The induction pattern generated after this 'pre-treatment' was unchanged (not shown).

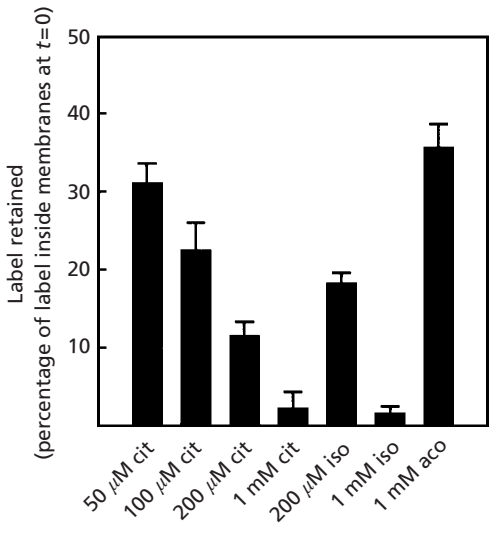

Fig. 4. Analysis of heterologous exchange with cis-aconitate. Label retained by RSO membrane vesicles of $E$. coli expressing CitM pre-loaded with $\left[1,5-{ }^{14} \mathrm{C}\right]$ citrate upon the addition of the indicated concentrations of citrate (cit), D-isocitrate (iso) and cisaconitate (aco). For details see the legend to Fig. 3. The bars and error bars give the mean + SD of the label retained at 20,40 and $60 \mathrm{~s}$ expressed as the percentage of the label inside the membranes at $t=0$. The $100 \%$ value varied between 0.6 and $1.2 \mathrm{nmol}(\mathrm{mg} \text { protein) })^{-1}$.

\section{Analysis of CitM substrate specificity}

RSO membrane vesicles prepared from E. coli cells expressing the $\mathrm{Mg}^{2+}$-citrate transporter CitM of B. subtilis catalysed the proton-motive-force-driven uptake of $\left[1,5-{ }^{14} \mathrm{C}\right]$ citrate at a rate of $52 \cdot 2 \mathrm{pmol} \mathrm{min}{ }^{-1}(\mathrm{mg}$ protein $)^{-1}$ at a $\left[1,5-{ }^{14} \mathrm{C}\right]$ citrate concentration of $4 \cdot 5 \mu \mathrm{M}$ (not shown; Boorsma et al., 1996). At a concentration of $1 \mathrm{mM}$, unlabelled citrate completely inhibited the uptake of labelled citrate, which is in agreement with the reported $K_{\mathrm{m}}$ for uptake ( $\sim 50 \mu \mathrm{M}$; Krom et al., 2000). DL-Isocitrate and D-isocitrate were also potent inhibitors of $\left[1,5-{ }^{14} \mathrm{C}\right]$ citrate uptake $(<10 \%$ residual activity), while the presence of $1 \mathrm{mM}$ of cis-aconitate in the growth medium resulted in $40 \%$ residual activity. None of the TCA cycle intermediates (succinate, fumarate, L-malate, 2-oxoglutarate and oxaloacetate) nor the related compounds D-malate and tricarballylate resulted in significant inhibition of $\left[1,5-{ }^{14} \mathrm{C}\right] \mathrm{citrate}$ uptake when they were present at concentrations of $1 \mathrm{mM}$ (not shown).

Inhibition of uptake does not prove that the inhibitor is transported, i.e. the inhibitor may bind to the transporter without being translocated. Heterologous exchange of labelled citrate and unlabelled substrates provides an assay to demonstrate translocation of the latter (Bandell \& Lolkema, 1999). Membrane vesicles prepared from E. coli cells expressing CitM were allowed to accumulate $\left[1,5-{ }^{14} \mathrm{C}\right]$ citrate driven by the proton motive force until a plateau was reached. Addition of FCCP, a protonophore that dissipates the proton motive force, to the assay mix resulted in very rapid efflux of the label from the lumen of the vesicles. In fact, all of the label was released within $10 \mathrm{~s}$ of the addition of FCCP (Fig. 3a). When instead of FCCP 

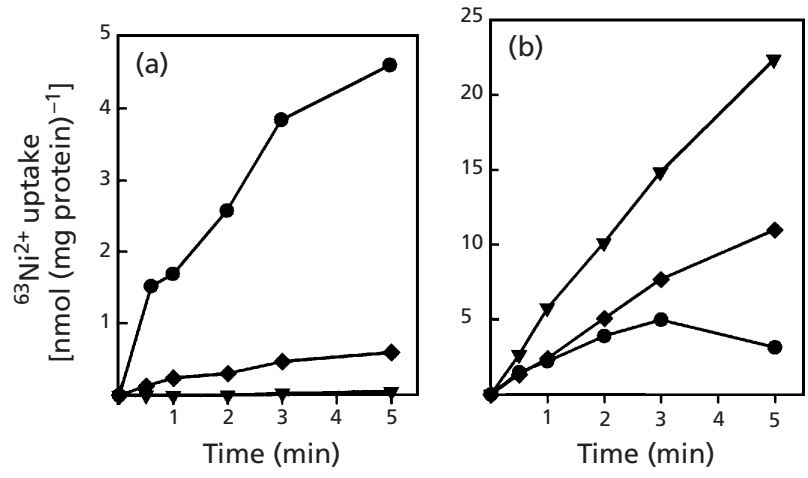

Fig. 5. ${ }^{63} \mathrm{Ni}^{2+}$ uptake in $E$. coli expressing CitM. The uptake of ${ }^{63} \mathrm{Ni}^{2+}$ in $E$. coli cells harbouring plasmid pWSK without an insert (a) and pWSKCitM carrying citM (b) was measured in the presence of no further additions ( $), 5 \mathrm{mM}$ citrate $(\boldsymbol{\nabla})$ or $5 \mathrm{mM}$ DLisocitrate $(\bullet)$.

$1 \mathrm{mM}$ of unlabelled citrate was added to the assay mix, the release of the label was also fast, but $10-20 \%$ of the label was still inside the membranes at $t=10 \mathrm{~s}$. Release of the label under these conditions is the result of homologous exchange during which the transporter transports unlabelled citrate into the vesicle in exchange for the exit of labelled citrate. To rule out the possibility that the addition of $1 \mathrm{mM}$ of citrate to the assay mix would dissipate the proton motive force, i.e. would mimic the effect of FCCP, the effect of $1 \mathrm{mM}$ of citrate on the accumulation level of $\mathrm{L}_{-}\left[\mathrm{U}_{-}{ }^{14} \mathrm{C}\right]$ proline in the $\mathrm{RSO}$ vesicles was measured as a control (Fig. $3 \mathrm{~b}$ ). No significant release of $\mathrm{L}_{-}\left[\mathrm{U}_{-}{ }^{14} \mathrm{C}\right]$ proline was observed under these conditions, while treatment of the assay mix with FCCP resulted in the loss of the label in $3 \mathrm{~min}$, suggesting that the addition of $1 \mathrm{mM}$ of citrate to the assay mix did not affect the magnitude of the proton motive force significantly.

Replacing unlabelled citrate in the assay with the same concentration of unlabelled D-isocitrate resulted in the same rapid release of the label from the membranes, while the addition of tricarballylate to the assay had no effect on release of the label (Fig. 3c). In agreement with the observed inhibition of $\left[1,5-{ }^{14} \mathrm{C}\right]$ citrate uptake by the two substrates, it follows that $\mathrm{D}$-isocitrate is transported by CitM and tricarballylate is not. Addition of $1 \mathrm{mM}$ of cis-aconitate to the pre-loaded membranes also resulted in the release of label; however, this release was incomplete, leaving approximately $35 \%$ of the label inside the membranes (Fig. 3c). During homologous and heterologous exchange, the transporter effectively equilibrates the specific radioactivity of the internal and external pools of substrates and, therefore, the extent of release of label from the membranes depends on the total pool of external exchangeable substrate (Bandell \& Lolkema, 1999). A titration with citrate as the exchangeable substrate showed that the addition of $50 \mu \mathrm{M}$ citrate to the assay resulted in the release of $\sim 70 \%$ of the label; the addition of $200 \mu \mathrm{M}$ citrate to the assay resulted in the release of $\sim 90 \%$ of the label (Fig. 4). The addition of the same amounts of D-isocitrate to the assay resulted in a similar release of label, showing that $\mathrm{D}$-isocitrate is the exchangeable substrate. The release of label observed with $1 \mathrm{mM}$ of $c i s$-aconitate corresponded to a concentration of $\sim 50 \mu \mathrm{M}$ exchangeable substrate and, therefore, was most likely due to a contaminant in cis-aconitate, presumably citrate or isocitrate. Contamination of a $1 \mathrm{mM}$ cis-aconitate solution with $50 \mu \mathrm{M}$ citrate would explain the observed inhibition of [1,5$\left.{ }^{14} \mathrm{C}\right]$ citrate uptake. In conclusion, citrate and D-isocitrate are substrates of CitM and cis-aconitate is not.

\section{${ }^{63} \mathrm{Ni}^{2+}$-isocitrate uptake by CitM}

Resting cells of E. coli TOP10 took up radioactive free ${ }^{63} \mathrm{Ni}^{2+}$ at a rate of $\sim 1.4 \mathrm{nmol} \mathrm{min}{ }^{-1}(\mathrm{mg} \text { cell protein })^{-1}$ (Fig. 5a). In the presence of $5 \mathrm{mM}$ citrate, which renders the ${ }^{63} \mathrm{Ni}^{2+}$ ions in the complexed state, uptake of ${ }^{63} \mathrm{Ni}^{2+}$-citrate by E. coli TOP10 was completely inhibited. The same concentration of isocitrate resulted in a residual uptake rate of ${ }^{63} \mathrm{Ni}^{2+}$ of $\sim 10 \%$, showing that isocitrate is somewhat less potent in complexing with $\mathrm{Ni}^{2+}$ than citrate. Under the same conditions as used for the above experiments, E. coli cells producing CitM showed increased uptake of ${ }^{63} \mathrm{Ni}^{2+}$ upon the addition of $5 \mathrm{mM}$ of citrate or DL-isocitrate to the assay, confirming that CitM transports $\mathrm{Ni}^{2+}$ complexed to citrate or DL-isocitrate (Fig. 5b).

\section{DISCUSSION}

The B. subtilis genome encodes at least three different transporters for citrate, all of which belong to the secondary type of transporter. $\mathrm{CimH}$, a member of the 2-hydroxycarboxylate transporter family, transports citrate and malate in symport with $\mathrm{H}^{+}$; CitM and $\mathrm{CitH}$, members of the MeCit transporter family, transport the complex of divalent metal ions and citrate (Krom et al., 2000, 2001). Moreover, the ORF yraO encodes a third protein in the MeCit family which is, potentially, a citrate transporter as well. In this study, we have shown that among the citrate transporters the $\mathrm{Mg}^{2+}$-citrate transporter CitM is the only transporter that is involved in the uptake of citrate during growth of B. subtilis on citrate as the sole carbon source. This conclusion is in line with the strict regulation of expression of citM by components in the medium. The physiological function of the other citrate transporters of B. subtilis is still elusive.

Citrate transporters are found in many bacterial species; these transporters allow bacteria to utilize citrate by its degradation via the TCA cycle or via one of the citrate- 
fermentation pathways (Bott, 1997). However, E. coli is an exception to this rule - although it contains all of the enzymes necessary for citrate metabolism, it cannot utilize citrate because it lacks a functional citratetransport system (Bott, 1997). In contrast to citrate, few reports are available on the utilization of isocitrate by bacteria and data on transporters with specificity for isocitrate are similarly scarce. It has been argued that transporters for citrate may also transport isocitrate (Kay, 1978), but this is definitely not generally true. For instance, the citrate transporters of the 2-hydroxycarboxylate transporter family (CimH of B. subtilis, CitP of lactic acid bacteria and CitS of Klebsiella pneumoniae) do not recognize isocitrate (van der Rest et al., 1992; Bandell et al., 1997; Krom et al., 2001). However, a tricarboxylate transport system has been described in Pseudomonas fluorescens that is induced by citrate and transports citrate and D-isocitrate. A second system in this organism is induced by tricarballylate and transports citrate, cis-aconitate and tricarballylate (Kay, 1978). Salmonella typhimurium has been reported to be able to grow on citrate, cis-aconitate and isocitrate by using a thus-far unique uptake system, which involves a periplasmic binding protein that specifically binds citrate, isocitrate and L-erythro-2-fluorocitrate (Somers et al., 1981; Sweet et al., 1984; Widenhorn et al., 1988). In this study, we have shown that B. subtilis can grow on isocitrate as a sole carbon source and that the $\mathrm{Mg}^{2+}-$ citrate transporter CitM is responsible for the uptake from the medium by three criteria. (i) The B. subtilis CitM-deficient strain CITMd lost the ability to grow on isocitrate completely (Fig. 1c, d), as was also observed for growth on citrate. (ii) Like citrate, isocitrate appeared to be an inducer of citM expression, on solid and in liquid media. (iii) Heterologous exchange experiments demonstrated that CitM transports isocitrate. Similar to citrate, isocitrate is taken up in complex with a divalent metal ion.

The results obtained with cis-aconitate are confusing; this confusion is likely to be caused by the presence of impurities in commercially available cis-aconitate preparations. Growth of $B$. subtilis in MSMYE medium resulted in complete lysis of the cells after $24 \mathrm{~h}$ incubation. When grown in the presence of cis-aconitate, we did not see additional growth of the organism, but the cells did not lyse and were still viable after $24 \mathrm{~h}$ incubation (not shown). Moreover, some B. subtilis growth enhancement was observed when $1 \mathrm{mM} \mathrm{Mg}{ }^{2+}$ was added to the medium in addition to cis-aconitate, strongly suggesting the involvement of CitM in the uptake of this TCA cycle intermediate (Fig. 1e). The citM-expression studies showed induction of CitM by cis-aconitate, but only after prolonged incubation of $B$. subtilis in the stationary phase. Unfortunately, the exchange studies revealed the presence of a contaminant in cis-aconitate $(\sim 5 \%)$ that was also a substrate of CitM and was, therefore, most likely to be citrate or isocitrate. No evidence was obtained that cis-aconitate itself is a substrate of CitM. We tentatively conclude that the growth effects and induction pattern observed when B. subtilis is grown in the presence of cis-aconitate, and previous claims made in the literature (McKillen et al., 1972), must be ascribed to impurities in the cisaconitate used; hence, cis-aconitate is not a growth substrate of $B$. subtilis.

In conclusion, B. subtilis is capable of growing on the TCA cycle intermediates citrate and isocitrate, mediated by CitM, on succinate and fumarate, mediated by DctP (Asai et al., 2000), and on L-malate. A consequence of the involvement of CitM in B. subtilis growth on citrate and isocitrate is that optimal growth of the organism requires higher concentrations of $\mathrm{Mg}^{2+}$ to be present than normally required (compare Fig. $1 \mathrm{~b}, \mathrm{~d}, \mathrm{~h}$ ). No growth of $B$. subtilis was detected when cis-aconitate, 2-oxoglutarate, D-malate, oxaloacetate or tricarballylate was the sole carbon source. The lack of growth of $B$. subtilis on 2-oxoglutarate that we observed is in contradiction with a report claiming growth of this organism on 2-oxoglutarate mediated by a low-affinity, inducible transport system with a $K_{\mathrm{m}}$ of $6.7 \mathrm{mM}$ (Fournier et al., 1972). Analysis of the B. subtilis genome (Kunst et al., 1997) provides no clue as to the identity of such a 2-oxoglutarate transporter.

CitM has been shown to take up citrate in complex with $\mathrm{Mg}^{2+}, \mathrm{Zn}^{2+}, \mathrm{Mn}^{2+}, \mathrm{Co}^{2+}$ or $\mathrm{Ni}^{2+}$. The improved growth of $B$. subtilis on isocitrate upon the addition of extra $\mathrm{Mg}^{2+}$ (Fig. 1c, d) to the growth medium and the ${ }^{63} \mathrm{Ni}^{2+}$ uptake experiments (Fig. 5) indicated that isocitrate is also transported in complex with $\mathrm{Mg}^{2+}$ and $\mathrm{Ni}^{2+}$. Further experiments showed that the uptake of $[1,5-$ $\left.{ }^{14} \mathrm{C}\right]$ citrate in the presence of $10 \mathrm{mM}$ of $\mathrm{Mg}^{2+}, \mathrm{Zn}^{2+}$, $\mathrm{Mn}^{2+}, \mathrm{Co}^{2+}$ or $\mathrm{Ni}^{2+}$ could, in all cases, be significantly inhibited by the presence of $1 \mathrm{mM}$ of isocitrate in the medium (not shown). These experiments suggest that the metal ion specificity in the complexes that are transported by CitM is the same for isocitrate and citrate, but it cannot be excluded that complexes with other divalent metal ions are not substrates for CitM. Citrate appears to be a stronger chelator of divalent metal ions than isocitrate. For instance, the complex formation constants for $\mathrm{Mn}^{2+}$-isocitrate and $\mathrm{Mn}^{2+}$ citrate (2.55 and $3.54 \mathrm{mM}$, respectively) (Martell \& Smith, 1977) indicate a 10-fold lower affinity of isocitrate for $\mathrm{Mn}^{2+}$ than citrate. In our experiments, about seven times more DL-isocitrate than citrate was required to inhibit the ${ }^{63} \mathrm{Ni}^{2+}$ uptake activity in whole cells of B. subtilis CITMd by $50 \%$. Four times less of the naturally occurring isomer $\mathrm{D}$-isocitrate was needed in whole cells of $B$. subtilis than L-isocitrate, indicating that $\mathrm{D}$-isocitrate is a better chelator than L-isocitrate (not shown). Consequently, optimal growth of B. subtilis on $\mathrm{D}$-isocitrate requires relatively high concentrations of divalent metal ions in the medium.

\section{ACKNOWLEDGEMENTS}

We would like to thank Professor Dr Sekiguchi for B. subtilis CITMd. This work was supported by grants from the Ministry of Economic Affaires of The Netherlands, in the framework of the 'IOP Milieutechnologie/Zware Metalen', project IZW97404. 


\section{REFERENCES}

Asai, K., Baik, S. H., Kasahara, Y., Moriya, S. \& Ogasawara, N. (2000). Regulation of the transport system for $\mathrm{C}_{4}$-dicarboxylic acids in Bacillus subtilis. Microbiology 146, 263-271.

Aymerich, S., Gonzy-Tréboul, G. \& Steinmetz, M. (1986). 5'Noncoding region $s a c R$ is the target of all identified regulation affecting the levansucrase gene in Bacillus subtilis. J Bacteriol 166, 993-998.

Bandell, M. \& Lolkema, J. S. (1999). Stereoselectivity of the membrane potential-generating citrate and malate transporters of lactic acid bacteria. Biochemistry 38, 10352-10360.

Bandell, M., Ansanay, V., Rachidi, N., Dequin, S. \& Lolkema, J. S. (1997). Membrane potential-generating malate (MleP) and citrate (CitP) transporters of lactic acid bacteria are homologous proteins. Substrate specificity of the 2-hydroxycarboxylate transporter family. J Biol Chem 272, 18140-18146.

Boorsma, A., van der Rest, M. E., Lolkema, J. S. \& Konings, W. N. (1996). Secondary transporters for citrate and the $\mathrm{Mg}^{2+}$-citrate complex in Bacillus subtilis are homologous proteins. J Bacteriol 178, 6216-6222.

Bott, M. (1997). Anaerobic citrate metabolism and its regulation in enterobacteria. Arch Microbiol 167, 78-88.

Fortnagel, P. \& Freese, E. (1968). Analysis of sporulation mutants. II. Mutants blocked in the citric acid cycle. J Bacteriol 95, 1431-1438.

Fournier, R. E., McKillen, M. N., Pardee, A. B. \& Willecke, K. (1972). Transport of dicarboxylic acids in Bacillus subtilis. Inducible uptake of L-malate. J Biol Chem 247, 5587-5595.

Goel, A., Lee, J., Domach, M. M. \& Ataai, M. M. (1995). Suppressed acid formation by cofeeding of glucose and citrate in Bacillus cultures: emergence of pyruvate kinase as a potential metabolic engineering site. Biotechnol Prog 11, 380-385.

Janausch, I. G., Zientz, E., Tran, Q. H., Kröger, A. \& Unden, G. (2002). $C_{4}$-dicarboxylate carriers and sensors in bacteria. Biochim Biophys Acta 1553, 39-56.

Kaback, H. R. (1983). The lac carrier protein in Escherichia coli. J Membr Biol 76, 95-112.

Kay, W. W. (1978). Transport of carboxylic acids. In Bacterial Transport, pp. 385-411. Edited by B. P. Rosen. New York: Marcel Dekker.

Krom, B. P., Warner, J. B., Konings, W. N. \& Lolkema, J. S. (2000). Complementary metal ion specificity of the metal-citrate transporters CitM and CitH of Bacillus subtilis. J Bacteriol 182, 6374-6381.

Krom, B. P., Aardema, R. \& Lolkema, J. S. (2001). Bacillus subtilis YxkJ is a secondary transporter of the 2-hydroxycarboxylate transporter family that transports L-malate and citrate. J Bacteriol $183,5862-5869$.

Kunst, F., Ogasawara, N., Moszer, I. \& 48 other authors (1997). The complete genome sequence of the Gram-positive bacterium Bacillus subtilis. Nature 390, 249-256.

Lolkema, J. S., Enequist, H. \& van der Rest, M. E. (1994). Transport of citrate catalyzed by the sodium-dependent citrate carrier of Klebsiella pneumoniae is obligatorily coupled to the transport of two sodium ions. Eur J Biochem 220, 469-475.

Martell, A. E. \& Smith, R. M. (1977). Critical Stability Constants, vol. 3: Other Organic Ligands. New York: Plenum.

McKillen, M. N., Willecke, K. \& Pardee, A. B. (1972). Citrate transport by Bacillus subtilis. In The Molecular Basis of Biological Transport, pp. 249-70. Edited by J. F. Woessner \& F. Huijung. New York: Academic Press.

Miller, J. H. (1972). Experiments in Molecular Genetics. Cold Spring Harbor, NY: Cold Spring Harbor Laboratory.

Somers, J. M., Sweet, G. D. \& Kay, W. W. (1981). Fluorocitrate resistant tricarboxylate transport mutants of Salmonella typhimurium. Mol Gen Genet 181, 338-345.

Sweet, G. D., Kay, C. M. \& Kay, W. W. (1984). Tricarboxylatebinding proteins of Salmonella typhimurium. Purification, crystallization, and physical properties. J Biol Chem 259, 1586-1592.

van der Rest, M. E., Molenaar, D. \& Konings, W. N. (1992). Mechanism of $\mathrm{Na}^{+}$-dependent citrate transport in Klebsiella pneumoniae. J Bacteriol 174, 4893-4898.

Warner, J. B. \& Lolkema, J. S. (2002). LacZ-promoter fusions: the effect of growth. Microbiology 148, 1241-1243.

Warner, J. B., Krom, B. P., Magni, C., Konings, W. N. \& Lolkema, J. S. (2000). Catabolite repression and induction of the $\mathrm{Mg}^{2+}-$ citrate transporter CitM of Bacillus subtilis. J Bacteriol 182, 6099-6105.

Wei, Y., Guffanti, A. A., Ito, M. \& Krulwich, T. A. (2000). Bacillus subtilis YqkI is a novel malic/ $\mathrm{Na}^{+}$-lactate antiporter that enhances growth on malate at low protonmotive force. $J$ Biol Chem 275, 30287-30292.

Widenhorn, K. A., Somers, J. M. \& Kay, W. W. (1988). Expression of the divergent tricarboxylate transport operon $(t c t I)$ of Salmonella typhimurium. J Bacteriol 170, 3223-3227.

Yamamoto, H., Murata, M. \& Sekiguchi, J. (2000). The CitST twocomponent system regulates the expression of the $\mathrm{Mg}$-citrate transporter in Bacillus subtilis. Mol Microbiol 37, 898-912.

Received 31 May 2002; revised 9 July 2002; accepted 12 July 2002. 